\title{
Isolation and Characterization of Multi Drug Resistant Pathogen from Soil Samples Collected From Hospital Disposal Site
}

\author{
Aindrila Saha ${ }^{1}$, Rashmi Das ${ }^{2}$, Moumita Dasgupta ${ }^{3}$, Subhadeep Dutta ${ }^{4}$, \\ Ghazala Haque ${ }^{5,}$ Dr. Arup Kumar Mitra ${ }^{6}$. \\ ${ }_{12,3,4,5,6}$ (Department of Microbiology, St. Xavier's Colllege,Kolkata,India)
}

\begin{abstract}
Antibiotic resistant bacteria was isolated from Uttarpara State General Hospital near Kolkata. The microscopical, biochemical tests suggested it to be Neisseria sp. Our major aim was to check the effect of several aqueous plant extracts on MDR and finding out tentative MIC value, study of any physiological changes brought about by the natural extract by phase contrast microscopy and ultimately to study any DNAase activity executed by the most successful plant extract on the multidrug resistant bacteria.
\end{abstract}

Keywords: Neisseria,Antibiotic drug resistance, DNAase, MIC

\section{Introduction}

Since the 1940s, these drugs have greatly reduced illness and death from infectious diseases. Antibiotic use has been beneficial and, when prescribed and taken correctly, their value in patient care is enormous. However, these drugs have been used so widely and for so long that the infectious organisms the antibiotics are designed to kill have adapted to them, making the drugs less effective. Many fungi, viruses, and parasites have done the same. Some microorganisms may develop resistance to a single antimicrobial agent (or related class of agent), while others develop resistance to several antimicrobial agents or classes. These organisms are often referred to as multidrug-resistant or MDR strains. In some cases, the microorganisms have become so resistant that no available antibiotics are effective against them. Large amounts of antibiotics used for human therapy resulted in the selection of pathogenic bacteria resistant to multiple drugs. Multidrug resistance in bacteria may be generated by one of two mechanisms. First, these bacteria may accumulate multiple genes, each coding for resistance to a single drug, within a single cell. This accumulation occurs typically on resistance (R) plasmids. Second, multidrug resistance may also occur by the increased expression of genes that code for multidrug efflux pumps, extruding a wide range of drugs. Due to the increase of resistance to antibiotics, there is a pressing need to develop new and innovative antimicrobial agents. Among the potential sources of new agents, plants have long been investigated [1]. Because, they contain many bioactive compounds that can be of interest in therapeutic. Because of their low toxicity, there is a long tradition of using dietary plants in the treatment of infectious disease and to combat the MDRs successfully [2].

\section{Materials And Methods}

Soil study, isolation, characterization of microorganism from hospital dumping site

The soil sample was well characterized and the observations were taken. The organisms obtained were first isolated in mixed culture and followed by pure culture techniques (four way method) to use the pure cultures for future use. The very basic Gram characterization was carried out of the three selected microorganisms to get a better idea about the organisms and probable antagonistic role were checked by the bacteria producing prominent red pigment in mixed culture but not in pure culture probably due to lack of competition.

\section{Isolation of microorganisms by Pour Plate Method}

$100 \mu$ of sample was poured onto the previously sterilized Nutrient Agar surface by a sterile spreader under aseptic condition. The plates were then placed in an incubator for 24 hours at $37^{\circ} \mathrm{C}$.

\section{Pure Culture Maintenance by Streak Plate technique}

The inoculating loop was sterilized by putting it in flame till red hot,after cooling it down, it was dipped into 95\% ethyl alcohol and further heated for proper sterilization.3 well distinguished colonies from spread plate were further streaked over three different Nutrient Agar plate surface by sterilized inoculating loop. These were the incubated for 24 hours at $37^{\circ} \mathrm{c}$. 


\section{Determination of Gram character of previously isolated microorganism by Gram staining method Procedure}

A smear of the three different microorganisms grown in NB was prepared on clean grease free glass slide by a sterile/flamed inoculating loop after cooling it. Smear was allowed to air dry and then heat fixed. Smear was flooded with crystal violet $\&$ allowed to stand for 1 minute and then gently washed with tap water. Smear was flooded with Gram Iodine and allowed to stand for 1 minute. Smear was decolorised / washed with 95\% ethyl alcohol until alcohol runs almost clear. Smear was counterstained with Safranin for 1 minute. Gently washed with tap water, air dried \& observed under compound microscope at 40X magnifications.

Antimicrobial resistance, susceptibility profiling of organisms using antibiotics and UV irradiation and study of antagonistic relationship

Concentration of antibiotic discs

Antibiotic discs of ampicillin $(10 \mathrm{mcg})$, tetracycline $(30 \mathrm{mcg})$, Co-triamoxazole $(25 \mathrm{mcg})$, nitrofurantoin (300 mcg), streptomycin(10 mcg).

The Muller Hinton agar was allowed to solidify in the Petri plates for the purpose of our experiment. Colony 1 , 2 and 3 previously inoculated into nutrient broths were spread evenly on the MH plates. Antibiotics of the above mentioned concentration were placed carefully on the plates and left for diffusion for some time. After that the plates were incubated at $37^{\circ} \mathrm{C}$ and later observations were noted down.

\section{UV irradiation}

The organism found resistant (Colony 2) to the action of some antibiotics (to be discussed in the result portion) was subject to mid UV of 280-350 nm for 5 minutes in a short UV chamber [3]. The above antibiotic disc diffusion technique was carried out again and observations were noted.

\section{Biochemical characterization of the isolated bacterial colonies and growth in Tryptic soy agar and other selective and differential media}

Initially an unknown bacterial culture was checked for catalase and oxidase activity [4]. The reagent used in oxidase test was N, N-dimethyl-p-phenylenediamine (DMPD). The presence of catalase enzyme in the test isolate is detected using hydrogen peroxide. The catalase test was done by placing a drop of hydrogen peroxide on a_microscope slide_Carbohydrate fermentation tests detect the ability of microorganisms to ferment a specific carbohydrate.In our experiment, we used glucose and sucrose with the multi drug resistant (MDR) organism isolated.With some knowledge about the nature of organisms we moved towards the task for growing the selected MDR on the following media. Tryptic soy agar, Chocolate agar (CHOC) or chocolate blood agar (CBA) and Mc Conkey agar culture medium were used [4].

The bacterial colonies isolated were subjected to catalase and oxidase test and observations were noted. The MDR obtained (previously during antibiotic disc diffusion technique) was used to carry out carbohydrate fermentation test by using 6\% glucose and 6\% sucrose in nutrient agar. The MDR obtained was made to grow in Tryptic soy agar, MacConkey and chocolate agar and colony characteristics were noted down.

\section{Inhibition of multiple drug-resistant bacteria by different natural plant extracts}

Due to the increase of resistance to antibiotics, there is a need to develop new and effective antimicrobial agents. Among the potential sources of new agents, plants have long been investigated because they contain many bioactive compounds that can be of interest in therapeutics. So, to combat the MDRs, different types of natural extracts are now used. In our experiment Marsilea, tea, turmeric, tobacco, garlic, ginger, neem, tulsi, pepper, chilli were used to check whether the MDR growth is inhibited or not.

Plant extracts were made by grinding them in mortar pestle, both in water and alcohol at a specific concentration given as follows:

Turmeric $(0.25 \mathrm{~g} / \mathrm{ml})$, Neem $(2 \mathrm{~g} / \mathrm{ml}), \quad$ Garlic and Ginger $(0.5 \mathrm{~g} / \mathrm{ml})$, Black pepper $(0.2 \mathrm{~g} / \mathrm{ml})$, Chilli $(1 \mathrm{~g} / \mathrm{ml})$, Tulsi $(2 \mathrm{~g} / \mathrm{ml}), \quad$ Clove $(3 \mathrm{~g} / 15 \mathrm{ml}), \quad$ Marsilea $(5 \mathrm{~g} / 15 \mathrm{ml}), \quad$ Kalmegh $(0.5 \mathrm{~g} / \mathrm{ml}) \quad$ and Tobacoo $(2.5 \mathrm{~g} / 10 \mathrm{ml})$.Then with the help of funnel and filter paper, the crude extracts were filtered and taken in test tubes and beakers. The culture (Multiple drug resistant) was spread over the agar in petriplate and 3, 4 wells were made by borer. The natural extracts were then given into the well by micropipette each $200 \mu$ l. This experiment was also done by disc-diffusion method for some of the natural extracts. The plates were then kept overnight in incubator at $37^{\circ} \mathrm{C}$.

\section{Determination of minimum inhibitory concentration (MIC) of garlic by cup- plate method}

MIC scores are important in diagnostic laboratories to confirm resistance of microorganisms to an antimicrobial agent and also to monitor the activity of new antimicrobial agents. We checked for minimum 
inhibitory concentration of the aqueous extract of garlic bulbs on the isolated MDR to recommend an alternative way to control the pathogen.

\section{Dilution of the Garlic extract:}

Initially the stock concentration- $1 \mathrm{gm} / \mathrm{ml}$ of garlic was made and it was further diluted into different concentration according to the following table:

\begin{tabular}{|c|c|c|}
\hline $\begin{array}{c}\text { Concentration of garlic extract } \\
(\mathrm{g} / \mathrm{ml})\end{array}$ & $\begin{array}{c}\text { Volume of sterile water added } \\
(\mathrm{ml})\end{array}$ & $\begin{array}{c}\text { Volume of garlic extract added from stock conc. } \\
(\mathrm{ml})\end{array}$ \\
\hline 0.1 & 1.35 & 0.15 \\
\hline 0.2 & 1.20 & 0.30 \\
\hline 0.25 & 1.125 & 0.375 \\
\hline 0.5 & 0.75 & 0.75 \\
\hline 0.75 & 0.375 & 1.125 \\
\hline 1.0 & - & 1.5 \\
\hline
\end{tabular}

$100 \mu 1 \log$ phase culture $\left(\mathrm{OD}_{600}=0.6\right)$ of the MDR organism was spread onto the MHA plate. Small cups were made with the help of puncher on those MHA plate and the cups were properly labeled.200 $\mu 1$ of each concentration of garlic extract were poured in each cup of MHA plate. The plates were incubated in BOD shaker at $37^{\circ} \mathrm{C}$ for overnight.

\section{MDR under inverted phase contrast microscope}

In our experiment we treated the cells with the MIC concentration of garlic extract and checked for any morphological or physiological changes on the MDR strain.

$50 \mu \mathrm{l}$ culture in the nutrient broth was placed onto a grease free slide and covered it with a cover-slip. The slides were observed under the phase contrast microscope. Garlic extract in sterile water (MIC dose: $0.25 \mathrm{~g} / \mathrm{ml}$ ) was added in the slide carefully.

\section{Effect of garlic extract on the genomic DNA of the MDR}

Culture was grown freshly Luria Bertani broth at $37^{\circ} \mathrm{C}$ up to cell O.D - 0.8 at $600 \mathrm{~nm}$ wavelength.34 ml of culture was taken in two different Falcon tubes and centrifuged at 6,000 r.p.m for 10minutes. The supernatant was discarded and the pellet was resuspended in $11.3 \mu \mathrm{l}$ of TE solution and then $226 \mu$ lysozyme was added and incubated at $37^{\circ} \mathrm{c}$ for one hour.Next $10 \%$ SDS was added so as to make a final concentration of $1 \%$ and incubated at $55^{\circ} \mathrm{C}$ for 15 minutes. An equal volume of Tris saturated phenol $(\mathrm{pH}=8)$ was added for phase separation and centrifuged at 10,000 r.p.m for 10 minutes.DNA comes into the aqueous layer and the other contaminants remain dissolved in the phenol layer. Hence, the aqueous layer was collected in a fresh Eppendorf. Next equal volume of phenol: chloroform (1: 1) mixture was added, centrifuged at 10,000 r.p.m for 10 minutes. Again the aqueous layer was collected after centrifugation and finally an equal volume of chloroform was now added to it and centrifuged at 10,000 r.p.m for 10 minutes. Aqueous layer was collected and $1 / 10^{\text {th }}$ volume of 3(M) sodium acetate $\left(\mathrm{CH}_{3} \mathrm{COONa}\right)$ and 2.5 times of absolute ethanol was added. The solution was mixed thoroughly doing upside down the vial, until a white precipitate of DNA was observed and then it was stored at $20^{\circ} \mathrm{C}$. The mixture was centrifuged at 10,000 r.p.m for 10 minutes. The supernatant was discarded and the pellet was suspended in $70 \%$ ethanol solution and washed. Again the ethanol solution containing the DNA was centrifuged at 10.000 r.p.m for 10 minutes. Supernatant was discarded. The precipitate was air dried and finally suspended in $680 \mu 1 \mathrm{TE}$ buffer. $80 \mathrm{ml}$ of $0.8 \%$ agarose gel (with $20 \mu 1$ of Ethidium Bromide) was casted .8 $\mu 1$ of each DNA sample along with $2 \mu \mathrm{l}$ gel loading dye (Bromophenol blue) was loaded into each well and the gel was then allowed to run till $75 \%$ at a current flow of 100 volts $/ \mathrm{cm}$. After the run was over, the gel was observed in a Gel-Doc under UV light.

III. RESULTS

Physical Characteristics of the Soil Sample was noted as follows

\begin{tabular}{|l|l|}
\hline Color & Dark brown, loamy \\
\hline Aroma & Earthy \\
\hline Texture & Granular \\
\hline pH & 8.3 \\
\hline Electrical Conductance & $174.4 \mu \mathrm{S}$ at $25^{\circ} \mathrm{C}$ \\
\hline Solubility & Insoluble in water. \\
\hline
\end{tabular}




\section{Isolation of microorganisms by Pour Plate Method and subsequently by pure culture}

Many well characterized colonies are obtained but 3 different colonies are being considered for further analysis. We at the end chose only colony number two which showed antibiotic resistance against the five antibiotics.

\section{Determination of Gram character of previously isolated microorganism by Gram staining method}

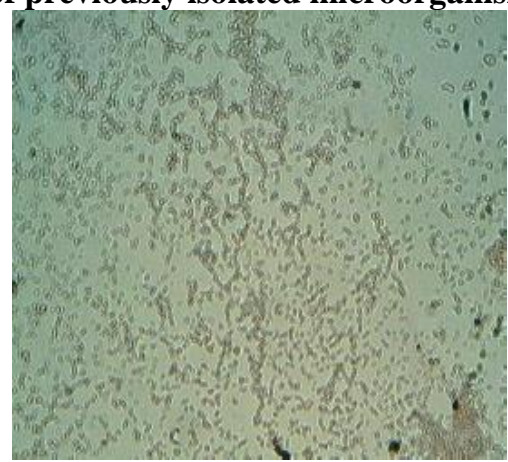

Figure 1: Gram negative cocci at 40x

The colony 2 shows no susceptibility towards the antibiotics

\begin{tabular}{|c|c|c|c|c|c|}
\hline Colony & $\begin{array}{c}\text { Ampicillin } \\
(\mathbf{1 0} \mathbf{~ m c g})\end{array}$ & $\begin{array}{c}\text { Tetracycline } \\
\mathbf{( 3 0} \mathbf{~ m c g})\end{array}$ & $\begin{array}{c}\text { Co-Triamoxazole } \\
(\mathbf{2 5} \mathbf{~ m c g})\end{array}$ & $\begin{array}{c}\text { Nitrofurantoin } \\
(\mathbf{3 0 0} \mathbf{~ m c g})\end{array}$ & $\begin{array}{c}\text { Streptomycin } \\
(\mathbf{1 0} \mathbf{~ m c g})\end{array}$ \\
\hline 2 & No zone & No distinct zone & $1.53 \mathrm{~mm}$ & No distinct zone & No zone \\
\hline
\end{tabular}

Table 1: Zone of inhibition given by the microorganism under 5 different antibiotics

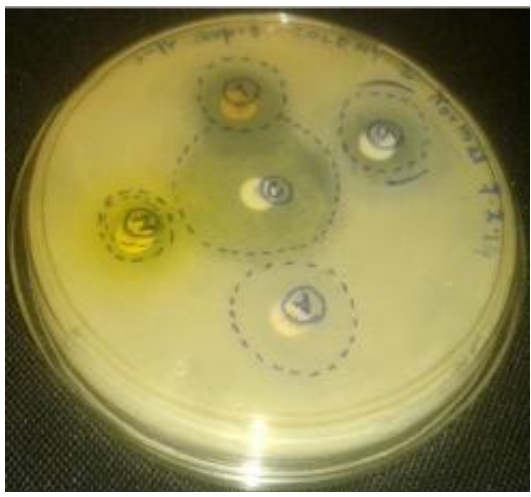

Figure2: Presence of no zone of inhibition except Co-triamoxazole at the centre

Antibiotic diffusion test after UV exposure:

Under UV exposure the susceptibility of the microbe towards the antibiotics changed.

\begin{tabular}{|c|c|c|c|c|c|}
\hline Colony & Ampicillin & Tetracycline & $\begin{array}{c}\text { Co- } \\
\text { triamoxazole }\end{array}$ & Nitrofurantoin & Streptomycin \\
\hline 2 & 2.12 & 0.86 & 1.54 & 0.28 & 1.16 \\
\hline
\end{tabular}

Table 2: After UV exposure at mid UV (280-350nm), the microbe becomes susceptible

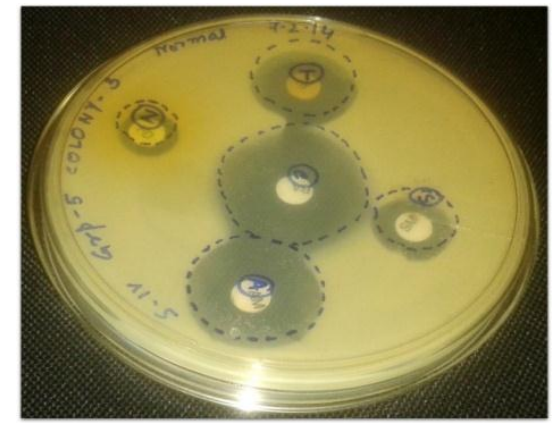

Figure 3: After UV exposure the susceptibility increases towards the antibiotics. 
Biochemical characterization of the isolated bacterial colonies and growth in Tryptic soy agar and other selective and differential media

\begin{tabular}{|c|c|}
\hline Test & Colony 2 \\
\hline Catalase & + \\
\hline Oxidase & + \\
\hline
\end{tabular}

Table3: Catalase and oxidase tests results
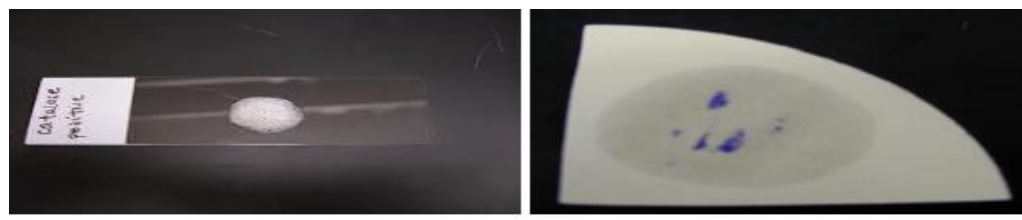

Figure 4: Left hand side shows catalase positive; right hand side shows oxidase positive

\begin{tabular}{|c|c|c|}
\hline Sugar & Gas & Acid \\
\hline Glucose & No & Produced (confirmed by methyl red) \\
\hline Sucrose & No & Not produced \\
\hline
\end{tabular}

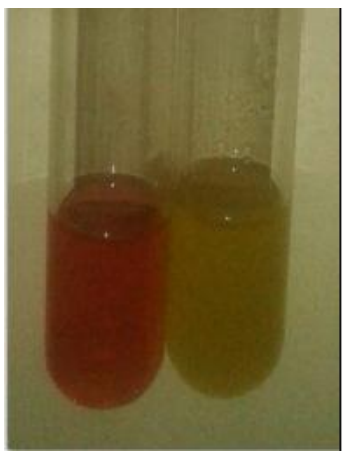

Figure 5: Left tube confirms utilization of glucose by the bacteria and the right tube shows no utilization of sucrose

\begin{tabular}{|c|c|c|c|}
\hline Agar & Colony pattern & Color & Inference \\
\hline Tryptic soy agar & $\begin{array}{c}\text { Small, opaque, raised. glistening } \\
\text { and smooth }\end{array}$ & $\begin{array}{c}\text { Organism can be non-fastidious } \\
\text { in nature }\end{array}$ \\
\hline McConkey & Raised, small colonies & Pink & Able to utilize lactose \\
\hline Chocolate agar & $\begin{array}{c}\text { Raised, small colonies, having } \beta- \\
\text { hemolytic colonies }\end{array}$ & $\begin{array}{c}\text { Able to utilize lysed red blood } \\
\text { cells }\end{array}$ \\
\hline
\end{tabular}

Table 4: Nature of growth in TSA, utilization of lactose (growth in McConkey) and nature of growth in chocolate agar
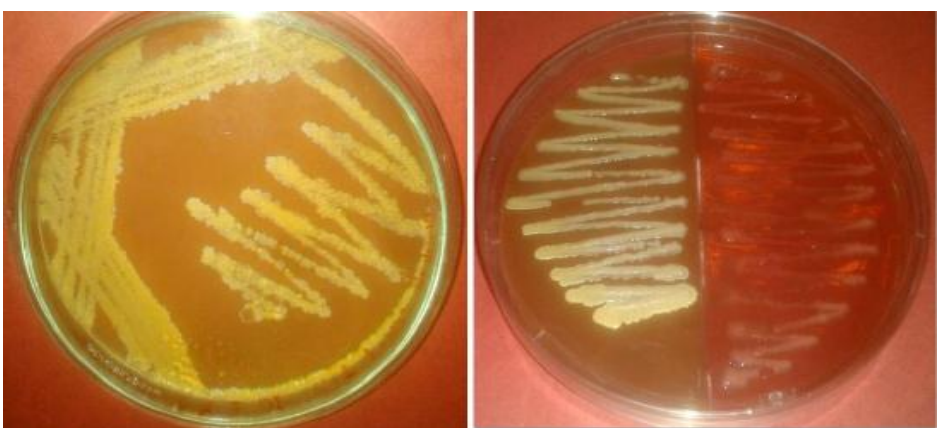

Figure 6: Left petriplate showing the growth on TSA and right showing the growth on chocolate and McConkey agar 
Inhibition of multiple drug-resistant bacteria by different natural plant extracts

Only garlic showed significant zone of inhibition against the MDR organism.

\begin{tabular}{|c|c|c|c|c|c|c|}
\hline \multirow{5}{*}{$\begin{array}{l}\text { Zone } \\
\text { Diameter } \\
(\mathrm{cm})\end{array}$} & \multicolumn{6}{|c|}{ NATURAL EXTRACTS } \\
\hline & Garlic & Tea & Marsilea & Tobacco & Neem & Ginger \\
\hline & 2.6 & 0.6 & 0.7 & 0.9 & 0.6 & 0.6 \\
\hline & 1.6 & 0.6 & 0.6 & 0.7 & 0.6 & 0.5 \\
\hline & 1.6 & 0.5 & 0.6 & 0.8 & 0.4 & 0.4 \\
\hline
\end{tabular}

Table 5: Garlic (Allium sativum showing maximum zone of inhibition compared to others)

Determination of minimum inhibitory concentration (MIC) of garlic by cup- plate method

After overnight incubation the zone of inhibition were observed and from the inhibition zone MIC value was determined which is tabulated below:

\begin{tabular}{|c|c|}
\hline Concentration of garlic extract $\mathbf{( g / m l )}$ & Inhibition zone obtained (mm) \\
\hline 0.1 & - \\
\hline 0.2 & 10 \\
\hline 0.25 & 18 \\
\hline 0.5 & 24 \\
\hline 0.75 & 32 \\
\hline 1.0 & 36 \\
\hline
\end{tabular}

The effect of garlic extract on the isolated MDR under inverted phase contrast microscope.

Single, small, round shaped bacterial (cocci), healthy cells were observed under 40X magnification in control (no garlic extract) having pendulum like motility. But just after addition of garlic extract the motility slowed down and ultimately stopped.

\section{Effect of garlic extract on the genomic DNA of the MDR}

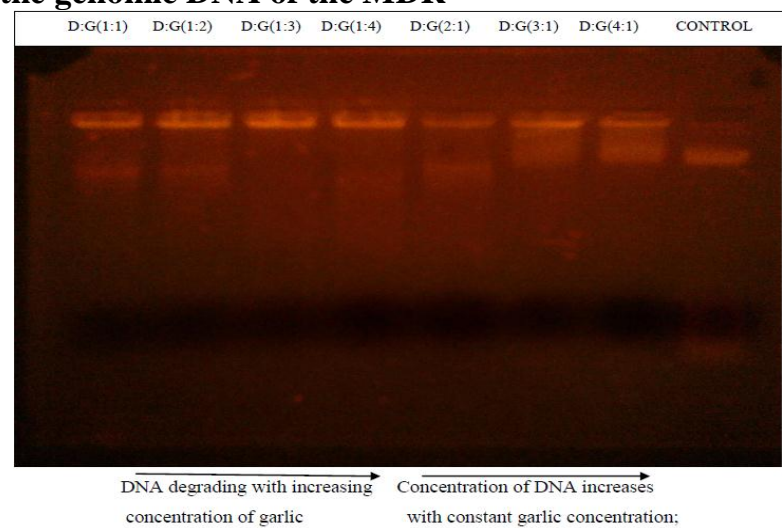

Figure7: With increasing garlic concentration the DNAase activity becomes prominent from the left as shown.

\section{Conclusion}

Hospital including operation theatre, ICU and patient ward are potent platform for spreading of pathogens among individuals [5]. High electrical conductance showed significant particulate matter and spurred our interest for more studies. The bacterial isolates purified from those hospital samples showed resistance against commonly used drugs. Based upon the microscopical studies, biochemical tests, and the colony characteristic on Nutrient agar, Tryptic soy agar, Chocolate agar and McConkey agar of the colony 2 we assumed the presence of Neisseria sp. It has been found that several non-pathogenic as well pathogenic strains of Neisseria are resistant to many antibiotics which we used such as $\beta$-lactamase producing Neisseria sp, tetracycline,streptomycin[6]. They state that cryptic plasmids of 24.5 MDa present in certain Gonococcal strains as well other Neisseria sp like Neisseria lactamica, $N$. subflava, $N$. sicca, $N$. mucosa, $N$. cinerea and mobilization of these plasmids to other strains have been observed[7]. The presence of genetically related $\beta$ lactamase plasmids in both $N$. gonorrhoeae and Haemophilus spp. strongly suggested that plasmid exchange between these two genera had occurred in nature (.Hence our findings were complying with the existing reports on Neisseria sp and Haemophilus sp.

It has also being reported that upon UV exposure the plasmid undergoes changes owing to mutations that make the MDR strains more susceptible towards the antibiotic. That is what we observed when we carried out the experiment with antibiotic discs after UV exposure. The most important observation noted was the 
degradation of genomic DNA into oligonucleotides with increasing concentration of garlic thus garlic has pronounced DNAase activity owing to its Selenium content [8].

One way is to shift towards natural remedies which need a thorough screening of the local flora and ultimately going for the one which is easily accessible with minimal side effects and effective against the pathogen. The organism which was isolated from the hospital soil was resistant to many of the commonly used broad-spectrum antibiotics such as Streptomycin, tetracycline, nitrofurantoin, ampicillin. But this multiple-drug resistant organism is greatly inhibited by the garlic extract. The MIC score of garlic on the experimental MDR organism lie between $0.2-0.25 \mathrm{~g} / \mathrm{ml}$. Even after the treatment with garlic extract, the motility of the MDR organism stopped. From this view point we may conclude that the isolated microorganism from hospital disposal site was sensitive to garlic extract and garlic in the form of many formulations can be taken to combat the growth of the MDR bacteria.

\section{References}

[1]. Nascimento Gislene G.F "Antibacterial activity of plant extracts and phytochemicals on antibiotic-resistant bacteria" Brazilian journal of microbiology 31(2000):247-256

[2]. Hammer K.A, Carson C.F “Antimicrobial activity of essential oils and other plant extracts" Journal of Applied Microbiology 86 (1999): 985-990

[3]. Maisch Tim "A new strategy to strategy to destroy Antibiotic Resistant Microorganism: Antimicrobial Photodynamic Treatment" Mini Reviews in Medicinal Chemistry 9(2009):974-983

[4]. Cappuccino JG, Sherman N. Microbiology : A laboratory manual. 7th ed., New Delhi; Pearson education Inc. and Dorling Kindersley: 2005:71-73.

[5]. Steel K.J "The Oxidase Reaction as a Taxonomic tool” J. gen. Microbiology 25(1961): 297-306

[6]. Chandan Prasad "Isolation and Characterization of Multi drug Resistant Super Pathogens from soil Samples Collected from Hospitals"Research Journal of Recent Sciences 2(2013), 124-129

[7]. Sparling Philip F "Genetic Transformation of Neisseria gonorrhoeae to Streptomycin Resistance" Journal of Bacteriology, 92(1966)

[8]. Roberts Marilyn C "Plasmids of Neisseria gonorrhoeae and Other Neisseria Species" Clinical Microbiology Reviews 2(1989) 1823.

[9]. Letavayova Lucia "Selenium: From cancer prevention to DNA damage" Toxicology 227 (2006) 1-14. 